\title{
Correction to: Squamous suture obliteration: frequency and investigation of the associated skull morphology
}

\author{
Silviya Nikolova ${ }^{1}$ (1) $\cdot$ Diana Toneva $^{1} \cdot$ Nikolai Lazarov $^{2,3}$
}

Published online: 28 August 2020

(c) Japanese Association of Anatomists 2020

\section{Correction to: Anatomical Science International https://doi.org/10.1007/s12565-020-00555-x}

In the original publication of the article, the word "complimentary" should be spelled as "complementary", in the last sentence of the "Abstract" and in the second sentence of the last paragraph of the "Discussion" section.

Publisher's Note Springer Nature remains neutral with regard to jurisdictional claims in published maps and institutional affiliations.

The original article can be found online at https://doi.org/10.1007/ s12565-020-00555-x.

Silviya Nikolova

sil_nikolova@abv.bg

1 Department of Anthropology and Anatomy, Institute of Experimental Morphology, Pathology and Anthropology With Museum, Bulgarian Academy of Sciences, Acad. G. Bonchev Str., B1. 25, 1113 Sofia, Bulgaria

2 Department of Anatomy and Histology, Medical University of Sofia, 1431 Sofia, Bulgaria

3 Department of Synaptic Signaling and Communications, Institute of Neurobiology, Bulgarian Academy of Sciences, 1113 Sofia, Bulgaria 